\title{
ANALYSIS OF THE OCCUPATIONAL HEALTH AND SAFETY AT SMES
}

\author{
DOI: $10.17261 /$ Pressacademia.2017.715 \\ RJBM- V.4-ISS.3-2017(14)-p.384-389
}

\section{Mehmet Colak, Tahsin Cetin}

Muğla Sıtkı Koçman University, Technology Faculty, Wood Working Industrial Engineering, Muğla, Turkey. cmehmet@mu.edu.tr Muğla Sıtkı Koçman University, Technology Faculty, Wood Working Industrial Engineering, Muğla, Turkey. tahsincetin@mu.edu.tr

\section{To cite this document}

Colak, M., and Cetin, T., (2017). Analysis of the occupational health and safety at SMEs. Research Journal of Business and Management (RJBM), V.4, Iss.3, p.384-389.

Permemant link to this document: http://doi.org/10.17261/Pressacademia.2017.715

Copyright: Published by PressAcademia and limited licenced re-use rights only.

\begin{abstract}
Purpose - In this study, understanding occupational health and safety conditions and determining health and safety risks at furniture enterprises have been proposed.

Methodology Surveys were conducted to measure the Occupational Health and Safety status of enterprises and the data obtained were analyzed by statistical programs.

Findings- Majority of participants stated that occupational health and safety applications at workplaces had a positive effect upon the productivity and quality of workplaces and forming a social perception on this issue would be useful for future employees.

Conclusion- The findings show that the majority of the personnels believe that occupational health and safety rules are important and they accept them.
\end{abstract}

Keywords: Occupational health and safety, SME, Personnel perception, Risk, Danger.

JEL Codes: J28, I10, J20

\section{IŞLETMELERDE (KOBi) iş SAĞLIĞI VE GÜVENLiĞi ANALizi}

\section{ÖZET}

Amaç - Bu çalışmada, mobilya sektöründe iş sağlığı ve güvenliği şartlarının anlaşılması, işletmelerdeki iş sağlığı ve güvenliği risklerinin tespit edilmesi ve işletmelerde acil durumlara yönelik önlemlerin ne derecede uygulanmakta olduğunun ortaya konulması amaçlanmıştır.

Yöntem - İşletmelerin İş Sağlığı ve Güvenliğine yönelik durumlarını ölçmek için anket uygulaması yapılmış olup, elde edilen veriler istatistik programlarıyla analiz edilmiştir.

Bulgular - Katılımcıların çoğunluğu iş yerindeki iş sağlığı ve güvenliği uygulamalarının o iş yerindeki iş verimini ve kaliteyi olumlu etkilediğini, bu konuda toplumsal bir algı oluşturmanın gelecek nesilde çalışan konumunda olacaklara fayda sağlayacağı bulgularımız arasındadır.

Sonuç - Elde edilen sonuçlara bakıldığında; işletmelerde ki personelin büyük bir çoğunluğu iş sağlığı ve güvenliği kurallarını olumlu yönde değerlendirdikleri ve kabullendikleri görülmektedir.

Anahtar Kelimeler- İş sağlığı ve güvenliği, KOBi, personel algısı, risk, tehlike.

JEL Kodları: J28, I10, J20

\section{GiRiş}

Güvenli ve sağlıklı çalışma ortamı, ülkelerin verimli ve doğru büyümelerinin de ön şartıdır. İ̧̧ sağlığı ve güvenliği çalışmalarına gereken önemin verilmemesi sonucunda iş kazaları meydana gelmekte ve meslek hastalıkları oluşmaktadır. İ̧̧ kazaları ve meslek hastalıkları sonuçları itibariyle işletmelere, ülkelere ve tüm insanlığa maddi ve manevi kayıpları da beraberinde getirmektedir (Tekin, 2014).

WHO ve ILO ilkelerine göre iş sağlığı ve güvenliği; tüm çalışanların bedensel, ruhsal ve toplumsal sağlık ve refahlarının en üst düzeye yükseltilmesi ve bu durumun korunması; işyeri koşullarının, çevrenin ve üretilen malların getirdiği sağlığa aykırı sonuçların ortadan kaldırılması; çalışanları yaralanmalara ve kazalara maruz bırakacak risk faktörlerinin ortadan kaldırılması; 
yine çalışanların bedensel ve ruhsal özelliklere uygun işlere yerleştirilmesi ve sonuç olarak işçilerin bedensel ve ruhsal gereksinimlere uygun bir iş ortamı yaratılması şeklinde tanımlanabilir (Bingöl, 2003 ).

Gelişen endüstrileşme ve sanayileşmeyle birlikte iş sağlığı ve güvenliği konusunda da bazı çalışmaların yapııması zorunlu olmak durumundadır. İşletmelerin, tüm üretim aşamalarında meydana gelecek olumsuzlukları ortadan kaldırabilmeleri için iş sağlığı ve güvenliği bakımından uygulayacakları korunma ve önleme politikalarına bağlı olduğu ve çalışanlarına bu farkındalığı kabullendirmesi gerçeğidir.

Dünyada ve ülkemizde mobilya sektörünün hızla geliştiği, büyüdüğü ve kendini yenilediği bu dönemde, ülkemiz mobilya sektöründe de gelişmeler ve yenilik hareketleri devam etmekle birlikte sektörün gelişmesi ve daha verimli hale gelmesinde iş sağ|ı̆̆ı ve güvenliği unsuru vazgeçilmez bir öneme sahiptir.

İş kazaları genellikle ülkelerin sanayileşme biçiminden, işletme şekillerinden, kaza istatistik ve araştırmalarının yetersizliğinden, denetim hizmetlerinin eksikliğinden, çalışanların niteliklerinden, işçi personel ve sorumluların önemsememesinden ve iş güvenliği bilincinin, kültürünün az olmasından kaynaklandığı bilgilerimiz arasındadır. İs kazalarının nedenleri genel özellikler göstermekle birlikte, ülke ve şehirlere göre kendine özgü bazı özelliklerde gösterebilmektedir.

Ülkemizdeki işletmelerin genellikle küçük ve orta ölçekli (Kobi) işletmeler olması, iş güvenliği organizasyonu, eğitim ve denetimi istenilen düzeyde olmaması, iş kazalarını arttırıı bir etki yapmaktadır. Ayrıca bu tür işletmelerde sigortasız işçi çalıştırmada büyük işletmelere oranla daha fazla olması ve resmi olmayan kaçak olarak çalıştıran işçilerin geçirdikleri kazalar kayıtlara geçmediğinden kaza istatistiklerinin tam güvenilirliği dahi tartışılabilir durumdadır. Buradan hareketle bu çalışmayla işletmelerde bir farkındalık oluşturmak ve söz konusu işletmelerin iş sağlığı ve güvenliğine etki eden faktörlerin belirlenmesi bakımından bu tür çalışmaların artırılması çalışan bireyi koruma adına önem arz etmektedir.

Bu kapsamda çalışmanın giriş ve birinci bölümünde araştırma yapılan sektörün durumu ve iş sağlığı ve güvenliği tehlikeleri ile işletmelere, sektöre yönelik genel bilgiler verilmiştir. İkinci bölümünde olan gereç ve yöntemlerde kullanılan metot ile ölçümlerin yapılışı ve kullanılan uygulanan metotlar hakkında bilgi verilmiştir. Üçüncü bölümde işletme değerlendirmesinin bulguları grafiklerle sunulmuş, ölçüm sonuçları verilmiş ve söz konusu bulgular açıklanmaya ve incelenen gözlemler aktarılmaya çalışılmıştır. Dördüncü bölümde ise risk değerlendirmesi ve ölçüm sonuçları doğrultusunda iş sağlığı ve güvenliği ile ilgili genel durum ortaya konulmuş ve çalışmanın bulguları ile literatürde yer alan çalışmaların sonuçları karşılaştırmalı olarak verilmeye çalışılmıştır. Son bölümde ise ölçüm ve gözlemlere dayanılarak söz konusu işletmelere ve personele yönelik iş sağlığı ve güvenliği ile ilgili tespit edilen durumlar ve öneriler paylaşıımıştır.

\section{LITERATÜR INCELEMESI}

Küreselleşen dünya pazarında hızla artan ve artmaya devam eden, işletmeler arası rekabetin sonucunda temel üretim faktörlerinden biri olan insan faktörünün önceki yıllara oranla daha fazla önem kazandığı gözlenmektedir. Bu yoğun rekabetle baş edebilmek için insan faktörünü merkeze alan yönetim anlayışlarının gelişmesi vesilesiyle insana ait iş güvenliği, iş sağlığı, iş doyumu gibi kavramlar önem kazanmıştır (Yıldırım ve diğ., 2015).

Yaşamının önemli bir kısmını iş yerinde geçiren insanın, buradaki güvenlik ihtiyacını karşılamak amacıyla, işçi sağlığı ve iş güvenliği adı altında bazı sistematik çalışmalar yürütülmüş ve işçi sağlığı ve iş güvenliği, disiplinler arası bir kavram ve çalışma alanı olarak tüm dünyaya yayılmıştır. Dünya'da iş kazası ve meslek hastalıklarından kaynaklanan kaybedilen yaşamlar düşünüldügünnde, işçi sağlığı ve iş güvenliği hakkındaki çalışmaların ve bu konuda gerçekleştirilmesi gereken ilerlemenin önemi gözler önüne serilmektedir (Uslu, 2014).

Gelişmiş ve gelişmekte olan ülkelerde toplam nüfusun yarısına yakın bir bölümünü çalışanlar oluşturmaktadır. Gelişen teknoloji ve sanayileşme ile birlikte işyerlerindeki kötü çalışma koşulları iş sağlığı ve iş güvenliğini ve buna bağlı olarak da toplum sağlığını tehdit eder hale gelmiştir. Sanayileşmiş ülkeler, günümüzde iş sağlığı ve iş güvenliği konusunda ciddi çabalar harcamak zorunda kalmışlardır. Söz konusu ülkelerin hepsi iş kazalarını ve meslek hastalıklarını olabildiğince en düşük düzeyde tutmak için uğraşmaktadırlar. Bu bağlamda, gelişmiş ülkelerde iş sağlığı ve iş güvenliği konusunun bağımsız bir bilim dalı haline geldiği ve genel toplum sağlığı içinde koruyucu sağlık hizmetlerinin önemli bir bölümünü oluşturduğu söylenebilir (Gerek, 1998).

Iş kazalarına ilişkin veriler ve ülkemizde yaşanan iş kazaları, meslek hastalıkları, sürekli iş görmezliğe sebep olan vakalar ve ölümlü kaza vakalarının Dünya ve Avrupa'yla karşılaştırmalı sonuçları doğrultusunda, ülkemizdeki iş kazası ve meslek hastalıkları konusundaki çalışmaların yetersiz kaldığı çok net olarak karşımıza çıkabilmektedir.

Türkiye'de yaşanan iş kazaları değerlendirildiğinde; Türkiye'nin Dünya'da en çok iş kazasının yaşandığı üçüncü ülke, Avrupa'da ise birinci ülke olduğu görülmekte ve bu konuda gerçekleştirilen çalışmaların diğer ülkelere kıyasla yetersiz olduğu açığa çıkmaktadır (Yıldırım ve diğ., 2015). Türkiye'de işçi sağlığı ve iş güvenliği eğitimlerindeki bilgi yetersizliği, verilen kurumsal bilgilerin davranışa dönüşmemesi ve iş güvenliği eğitimindeki süreksizlik verilen eğitimin kalıcı olmasındaki en önemli engellerdir (Aydın vd., 2012). 
iş kazası ve meslek hastalıklarını azaltmanın yollarından biri, işverenlerin konuya ilişkin yükümlülükleri ve sorumlulukları hakkında yeterli bilgi sahibi olmalarıdır. İşverenler, yükümlülüklerini yerine getirdikleri takdirde hem iş kazası ve meslek hastalıklarında önemli bir azalma olacak, hem de söz konusu kaza ve hastalık hallerinde idari, cezai ve hukuki yaptırımlarla karşılaşmayacaklardır (Baycık, 2007).

İşletmelerde karşılaşılan en önemli insan kaynakları sorunlarından biri, çalışanların emniyetli ve sağlıklı bir çalışma ortamına sahip olmamalarıdır. İ̧̧letmelerin daha iyi rekabet koşullarına ulaşabilmesi için çalışanların iş sağlığı ve güvenliği konusunda planlı ve sistemli çalışmalar yürütmeleri gerekmektedir (Anonim 1, 2017). Ülkemizdeki işletmeler genellikle küçük ve orta ölçekli işletmelerde, iş güvenliği organizasyonu, eğitim ve denetimi istenilen düzeyde olmaması, iş kazalarını arttırıcı bir etki yapmaktadır. Ayrıca bu tür işletmelerde sigortasız işçi çalıştırmada büyük işletmelere oranla daha fazladır. Kaçak olarak çalıştıran işçilerin geçirdikleri kazalar kayıtlara geçmediğinden kaza istatistiklerinin tam güvenilirliği dahi tartışılabilir (Camkurt, 2007).

İş sağlığı ve iş güvenliğinin temel amaçlarının çalışanları korunmak, üretim güvenliğini ve üretim verimliliğini sağlamak olduğu unutulmamalıdır. Çalışanları korumak noktasında iş sağlığı ve iş güvenliği konularını kapsayan koruma faaliyetlerinin her işletmede yerine getirilmesi gerekmektedir (Gedik ve İlhan, 2014).

İş kazaları ve meslek hastalıklarının tüm dünyada olduğu gibi ülkemizde de hem ekonomik açıdan hem de yönetsel açıdan birçok olumsuzlukları beraberinde getireceği malumdur. Herhangi bir sebep olmadan, beklenmeyen bir anda, belli bir amaç güdülmeden ve rastgele gerçekleşen kaza olayının her yönü ile araştırılması ve sürekli çözümler geliştirilmesi iş kazası ve meslek hastalıklarını azaltmada gerekli olmazsa olmazlardandır (Gedik ve İlhan, 2014).

İş sağlığı ve iş güvenliğinin temel amacı çalışanları korunmak, üretim güvenliğini ve üretim verimliliğini artırmak ve ayrıca her şeyden önce bireyin yaşamı ve güvenliği işten önce gelir kültürünü yerleştirmeye çalışmak olduğudur. Çalışanları korumak noktasında iş sağlığı ve iş güvenliği konularını kapsayan koruma faaliyetlerinin her yaşam alanında yerine getirilmesi ve bunu her zaman öncelikli hale getirmek sağıklı güvenli insan yaşam kalitesi adına önem arz etmektedir.

Yönetici pozisyonunda olmayan çalışanlar da yaptıkları işlerle ilgili olarak aldıkları eğitim doğrultusunda bilinçli, tedbirli, disiplinli davranmalı, moral bozukluğu ve yorgunluk içinde bulunmamalı, her şeyden önce kendi hayatına ve sağlığına önem vermeli, işyerlerinde emniyetle çalışmalarından daha önemli bir şey olmadığını ve işin bitiminden sonra kendilerini evde bekleyenlerin olduğunu unutmamalıdır (Çelikdin, 1999).

\section{VERI VE YÖNTEM}

Günümüzde iş yerlerinde, iş ahlakı, etik değerler ve günümüz işletme anlayışı bakımından iş sağlığı ve güvenliği her şeyin önünde gelmektedir. Bunun yanında bir işletmenin iyi bir şekilde düzenlenmesinin o iş yerinde çalışanların iş verimini artırdığı, iş kazalarını azalttığı ve işçi-işveren ilişkilerini olumlu yönde etkilediği de bir gerçektir. Ayrıca bir ülkenin gelişmesi; insan gücünün, doğal kaynakların, her türlü makine-techizatın ve teknik insan gücünün korunmasına, aynı zamanda etkili ve verimli bir şekilde kullanılmasına bağlıdır.

Ahşap ve mobilyacılık sektöründe en çok karşılaşılan sağlık sorunları, kazalardan kaynaklanmaktadır. Bu kazalar genellikle genç ve deneyimsiz işçiler arasında daha sık görülmektedir. Sektörün yapısı itibariyle, çalışanların mesleki bir eğitime tabi olmuş olma oranlarının düşük olması ve işin makine başında öğrenilmesi kaza riskini arttırmaktadır. Bu kazaların önemli bir bölümü sıradan sıyrıklar ve kesiklerden oluşmaktadır. Ancak sıyrıkların ve kesiklerin enfeksiyon kapması sonucu ciddi hastalıklar da ortaya çıkabilir. Bunlarla birlikte kullanılan makinaların keskin olması ellerin ve parmakların kopmasına (amputasyon) da neden olabilir. Ayrıca makinalar kullanılırken duruş bozuklukları, kas-iskelet sistemi ile ilgili rahatsızlıklara neden olmaktadır. Mobilya ve ahşap işleme sektöründe görülen kazalar ve meslek hastalıklarını önlemek konusunda öncelikle makinalarda ve ortamda alınacak önlemlerin, eğer bu başarılamazsa Kişisel Koruyucu Donanımların kullanımının büyük önemi vardır. Öncelikle işçiler kullandıkları makinalar ve ortamdaki riskler konusunda eğitilmeli, risk analiz yöntemleri kullanılarak görülen ve görülmesi muhtemel kazaların nasıl ortadan kaldırılabileceği incelenmelidir. Eğer var olan tehlikeler ortadan kaldıılamıyorsa o zaman bu tehlikelerle karşılaşma riski azaltılmalıdır. Bu tehlikelerle karşılaşıldığında sakatlanma ve yaralanma riskini aza indirmek için ise kişisel koruyucu donanımların uygun kullanımının büyük önemi vardır (Anonim 2, 2015).

İş sağlığı ve iş güvenliği kapsamında yürürlükte olan kanun ve gerek ülke genelinde gerekse lokal bazda yapılan daha önceki ampirik araştırmalardan yararlanılarak oluşturulan anket formu yardımıyla veriler elde edilmiştir. Çalışma kapsamında kullanılan anket formu demografik değişkenleri ölçmek için 7 soru ile personel yaklaşımlarını, algılarını, tutumlarını ve davranışlarını ölçmek için oluşturulan 3’lü Likert ölçeği ile 16 soru yöneltilmiş toplam 182 adet anket uygulanmıştır. Anket uygulamasında ki ölçek soruları daha önce bu alanla ilgili yapılmış çalışmalardan da esinlenerek çalışmamızın kapsamına göre yeniden düzenlenerek hazırlanmıştır. 


\section{BULGULAR VE TARTIŞMA}

Katılımcı personelin \% 84'ü bay, \% 16'sı bayandır. Bayan sayısının az olması düşündürücü olmakla birlikte onların istihdama yönelik adımların da atılması gerektiği karşımıza çıkmaktadır. Yaş aralıkları olarak genç iş görenlerin \% 59 oranında olması genç istihdamına yönelik sevindirici olmakla beraber tecrübesiz olmaları iş sağlığı ve güvenliği bakımından her türlü önlem ve uygulamanın yapılması gerektiğidir. Çalışanların \% 49'u üretim hattında çalıştığını, \% 72'si iş kazası ve meslek hastalığıyla karşılaşmadığını belirtmiştir. Çalışma süresi içerinde çalışanların \%60’ı isG eğitimi konusunda bilgilendirildiğini, yaklaşık \%50'si çalıştıkları sektörde yaşanabilecek iş kazası ve meslek hastalıklarını araştırdığını, \%70'i meslek hastalığıyla karşılaşmadığını ve \%60'ı çalıştığı iş yerinde yeni bir araç veya gereç alındığında doğru bir şekilde nasıl kullanılacağı hakkında uygulamalı bir eğitim verildiğini belirtmiştir.

Tablo 1: Katılımcıların Demografik Bilgileri

Sayı Frekans (\%)

1-Katılımcıların Cinsiyeti ?

A) Bay

B) Bayan

2-Katılımcıların Yaşları ?

$\begin{array}{llll}\text { A) } & 18-30 \text { arası } & 108 & 59 \\ \text { B) } & 31-40 \text { arası } & 48 & 26 \\ \text { C) } & 41 \text { ve üzeri } & 26 & 15\end{array}$

3- Katılımcıların çalıştıkları birimler?
A) Üretim
$90 \quad 49$
B) Montaj
$24 \quad 13$
C) Sevkiyat
D) Diğer

$30 \quad 16$

$38 \quad 22$

4- Çalışma hayatınız boyunca İş Sağlığı ve Güvenliği (iSG) konusunda bilgilendirildiniz mi?
A) Evet
$110 \quad 60$
B) Hayır

$72 \quad 40$

5- Çalıştığınız sektörde yaşanmış-yaşanabilecek iş kazası ve meslek hastalıklarını araştırdınız mı?
A) Evet
$88 \quad 48$

B) Hayır

$94 \quad 52$

6- Çalışma yerinde İ̧̧ Kazası veya Meslek hastalı̆ı̆ıla karşılaştınız mı?
A) Evet
$51 \quad 28$
B) Hayır

$131 \quad 72$

7- Çalıştığınız iş yerinde yeni bir araç veya ekipman alındığında doğru bir şekilde nasıl kullanılacağı hakkında uygulamalı bir eğitim verildi mi?

\begin{tabular}{llll} 
A) Evet & & 111 & 61 \\
B) Hayır & & 71 & 39 \\
& Toplam & $\mathbf{1 8 2}$ & $\mathbf{1 0 0}$ \\
\hline
\end{tabular}

Tablo 2'ye göre; söz konusu işletmelerde personele yönelik Kişisel Koruyucu Donanımların (KKD) ve teknik ekipmanların çoğunluğuna tedarik edildiği, sağlık ve güvenlikle ilgili tedbirlere uyulup uyulmadığının denetlendiği ve gerekli tedbirlerin alındığı fakat düzenli aralıklarla risk değerlendirmesinin tamamında düzenli olarak yapılmadığı, çalışanların acil bir durumda nasıl bir yol izleyeceği hangi planı uygulayacağı konusunda yetersizlikler olduğudur. Söz konusu işletmeler de isG'ye yönelik tüm materyaller olsa bile çalışanların bu materyalleri uygulamalı olarak nasıl kullanılacağını bilmesi ve ne yapması gerektiğini çok iyi bilecek şekilde öğrenmelidir.

Tablo 2: Çalışılan Yerde İş Sağlığı ve Güvenliği Konusunda Yönetimsel Önlem, Tedbir ve Uygulamalar

(\%) 1-Katılıyorum 2-Kararsızım 3- Katılmıyorum Toplam

1- İ̧letmemizde çalışanlara sağlık ve güvenlik ile ilgili

Kişisel Koruyucu Donanımlar (KKD) sağlanır. 122

2- İşletmemiz de sağlık ve güvenlik ile ilgili tedbirlere uyulup uyulmadığı denetlenir.

26

34

182

- Issletmemizde sağlık ve güvenlik ile ilgili gerekli tedbirler alınır. 107

4- İşletmemizde sağlık ve güvenlik için gerekli olan teknik ekipmanlar bulunur.

5- Ișletmemizde düzenli aralıklarla risk değerlendirmesi yapılır. 105

6- İşletmemizin olası bir acil duruma karşı (yangın v.b.) tüm çalışanların bildiği bir eylem planı vardır.

$\begin{array}{lll}60 & 30 & 182\end{array}$

$23 \quad 52 \quad 182$

$\begin{array}{lll}25 & 42 & 182\end{array}$

$55 \quad 22 \quad 182$


Tablo 3'e göre; çalışan personelin çoğunluğu işyerinde sağlık ve güvenlik bakımından bir tehdit ile karşılaştıklarında derhal İşyeri yönetimine haber verdikleri, iş sağlığı ve güvenliği eğitimlerinden öğrendikleri bilgileri, iş yaparken genelde uyguladıkları, işlerini yaparken kendi ve diğer arkadaşlarının sağlık ve güvenliklerini genelde tehlikeye düşürmediklerini, işyerindeki makine, araç ve gereçleri kurallara uygun bir şekilde kendilerine verilen Kişisel Koruyucu Donanımları (KKD) doğru bir şekilde tam anlamıyla kullanmadıkları belirlenmiştir.

Tablo 3: Çalışanların İ̧̧ Sağlığı ve Güvenliği Kriterlerine Göre Çalışması

(\%) 1-Katılıyorum 2- Kararsızım 3-Katılmıyorum Toplam

1-Çalışma arkadaşlarım işyerinde sağlık ve güvenlik bakımından bir tehdit ile karşılaştıklarında derhal İşyeri yönetimine haber verirler. 102

2- Çalışma arkadaşlarım iş sağlığı ve güvenliği eğitimlerinden öğrendikleri bilgileri, iş yaparken uygularlar.

$\begin{array}{llll}102 & 66 & 14 & \mathbf{1 8 2} \\ 115 & 50 & 17 & \mathbf{1 8 2} \\ 114 & 51 & 17 & \mathbf{1 8 2} \\ 102 & 50 & 30 & \mathbf{1 8 2} \\ 109 & 60 & 13 & \mathbf{1 8 2} \\ 104 & 53 & 25 & \mathbf{1 8 2}\end{array}$

3- Çalışma arkadaşlarım işlerini yaparken, kendi sağlık ve güvenliklerini tehlikeye düşürmezler.

4- Çalışma arkadaşlarım işlerini yaparken, diğer personelin sağlık ve güvenliklerini tehlikeye düşürmezler.

5- Çalışma arkadaşlarım işyerindeki makine, araç ve gereçleri kurallara uygun bir şekilde kullanır.

6- Çalışma arkadaşlarım kendilerine verilen Kişisel Koruyucu Donanımları (KKD) doğru bir şekilde kullanırlar.

Tablo 4'e göre; çalışanların çoğunluğu meslek hastalıkları ve nedenleri hakkında bilgi sahibi olmadığı, iş hayatları ile ilgili yasal hak ve sorumlulukları hakkında fazla bilgi sahibi olmadığı ve koruyucu ekipmanları kendi isteğiyle kullanmadıkları sonucu elde edilmiştir. Bu veriler doğrultusunda güvenlik kültürü oluşturmanın ne kadar gerekli olduğu bu çalışmalarla karşımıza çıkmaktadır.

Tablo 4: Çalışanların İş Sağlığı ve Güvenliği Konusundaki Farkındalık Seviyeleri

1- Çalışma arkadaşlarım, meslek hastalıkları ve nedenleri hakkında bilgi sahibidir.

(\%) 1-Katılıyorum 2- Kararsızım 3- Katılmıyorum Toplam

2- Çalışma arkadaşlarım, iş hayatları ile ilgili yasal hak ve sorumlulukları hakkında bilgi sahibidir.

\begin{tabular}{llll}
83 & 61 & 38 & $\mathbf{1 8 2}$ \\
65 & 71 & 46 & $\mathbf{1 8 2}$ \\
67 & 66 & 49 & $\mathbf{1 8 2}$ \\
91 & 43 & 48 & $\mathbf{1 8 2}$ \\
\hline
\end{tabular}

3- Çalışma arkadaşlarım, meslek hastalıklarından korunma yolları hakkında bilgi sahibidir.

4- Çalışma arkadaşlarım, koruyucu ekipmanları kendi isteğiyle kullanır.

\section{SONUÇ VE ÖNERILER}

İş kazası ve meslek hastalıklarını azaltmak için, işverenlerin konuya ilişkin yükümlülükleri ve sorumlulukları hakkında yeterli bilgi sahibi olmalarıdır. İşverenler, zorunlu ve yapması gereken insani yükümlülüklerini yerine getirdiği takdirde hem iş kazası ve meslek hastalıklarında önemli bir azalma olacağı, hem de söz konusu kaza ve hastalık hallerinde idari, cezai ve hukuki yaptırımlarla karşılaşmayarak önemli bir giderden kurtulmuş olacağıdır.

İs kazaları ve meslek hastalıkları sonucu ortaya çıkan kayıpların maliyeti, ülke ekonomisi bakımından değerlendirildiğinde olumsuz sonuçlar ortaya çıkmaktadır. Yetişmiş insan gücü kaybının ve bunların iş göremez duruma düşmesinin ülke ekonomisine vereceği gizli dolaylı maliyet ile ülkeye geri kazanılması güç zararlar verdiği açıktır. Ayrıca bu tür zararlardan korunmak için önce iş sağlığı ve güvenliğine yönelik adımların atılarak devlet КOBi arasında etkileşimli kuralların uygulanması ve kabullenilmesi gerektiğidir.

Bütün bu çalışmaların yanı sıra firmaların güçlü bir iş güvenliği kültürünü inşa ederek benimsemesi muhtemelen yaşanabilecek iş kazaları ve meslek hastalıklarının önlenmesinde etkili olacağıdır. Burada dikkat çekilmesi gereken en büyük faktör önce insan gelir mantalitesinin oluşturulması ve bunu içselleştirmesi ve tüm işletme üretim aşamalarında bilmesi gerektiğidir.

Çalışanların İş Sağlığı ve Güvenliği konusundaki farkındalık seviyeleri ile İ̧̧ Sağlığı ve Güvenliği kriterlerine göre çalışmasının faktör değerleri bakımından düşük değerde olması hala güvenlik kültürünü kendi isteğimizle değil de başkalarının istek ve doğrultusunda yaptığımızdır. Bu algıyı olumluya çevirmenin unsurlarından en önemlisi uygulamalı olarak iş sağlı̆̆ı güvenlik uygulamalarını yaparak gerçekleştirmemizdir.

Günümüzde, daha iyi çalışma standartları ve teknolojik gelişmelere rağmen, iş kazaları ve meslek hastalıkları dünya genelinde artmasının; sanayileşmiş ülkelerdeki emek yoğun sanayi üretiminin, emeği ucuz ve sosyal koruma düzeyi düşük 
gelişmekte olan ülkelere kaydırılmasının neden olduğu öngörülebilir. Ani gelişmeye uygun olmayan işletme şartları ve çalışan işçi bireylerinin hazırlıksız yakalanmaları bunlara sebebiyet verdiği gerçeğidir.

Sonuç olarak anketlere katılım sağlayan işletmelerdeki personelin verdikleri cevaplara bakıldığında, büyük bir çoğunluğunun iş sağlığı ve güvenliğine bakışının pozitif olduğu, bu olumlu algının gençlerin iş hayatına atıldıklarında iş kazasına maruz kalma riskinin düşük olabileceği ve çalışma döneminde aldıkları uygulamalı iş sağlığı ve güvenliği eğitiminin verimli olacağının bir göstergesidir. Eğitim-öğretim yıllarında verilen her türlü uygulamalı veya teorik İş Sağlığı ve Güvenliği derslerinin ve seminerlerinin toplumun kanayan yarası haline gelen iş kaza ve meslek hastalıklarını önlemede önemli bir etken olacağı öngörülerimiz arasındadır. Ayrıca toplumda "önce sağıık ve güvenlik gelir" algısının oluşturulması bizden sonraki nesillere örnek olması bakımından önemlidir. İşletmelerde iş sağlığı ve güvenliğine yönelik yapılacak yatırımlar sayesinde meslek hastalıklarının, iş kazalarının, işyeri ölümlerinin azalması ve işletmelerde yüksek verimlilik getirisi sağlayacağıdır.

*Bu çalışma Global İ̧sletme Araştırmaları Kongresinde (GIAK-2017/PreeAcademia Procedia) sunulan 2 bildirinin geliştirilmesiyle derlenmiştir.

\section{REFERENCES}

Anonim 1, 2017. OHSAS 18001 İş sağlığı ve güvenliği yönetim sistemi, http://www.standartkalite.com/ohsas18001_nedir.htm Erişim tarihi: 30.03.2017

Anonim 2, 2015. http://www.isguvenligi.net/iskollari-ve-is-guvenligi/ahsap-ve-mobilya-imalat-sektorunde-is-sagligi-ve-guvenligi/ (Erişim Tarihi: 25.12 .2015 )

Aydın, U., Karaca, N.G., Özgüler, V.C., Karaca, E., Güngör, Y. ve Demir, M., 2012. "Türkiye'de İş Sağığı ve Güvenliği Eğitiminin İş Kazaları ve Meslek Hastalıklarının Önlenmesindeki Rolü”, Anadolu Üniversitesi Bilimsel Araştırma Projesi.

Bingöl, D., 2003. İnsan Kaynakları Yönetimi, 5. Basım, Beta, s.455, İstanbul.

Camkurt, M.Z., 2007. İşyeri Çalışma Sistemi Ve İşyeri Fiziksel Faktörlerinin İş Kazaları Üzerindeki Etkisi, TÜHis İş Hukuku ve İktisat Dergisi Cilt: 20 Sayı: 6 , Cilt: 21 Sayı: 1 Mayıs / Ağustos 2007.

Çelikdin, B., 1999. “İşçi Sağlığı ve İş Güvenliği İş Kazalarının Önlenmesi”, TUDEV İş Dünyası Dergisi, Sayı:6, Yıl:1999, s. 16-18.

Baycık, G., 2007. İş Sağlığı ve Güvenliği Bildiriler Kitabı(Inş̧aat İşyerlerinde İşverenin isG Yükümlülükleri ve Sorumluluğu), İstanbul: İMO Yayını, Ekim, s. 41.

Gedik, T., ve İlhan, A., 2014. Sakarya ili mobilya imalatçılarında iş sağlığı ve iş güvenliği üzerine bir inceleme, SDÜ Orman Fakültesi Dergisi, Sayı: 15/123-129, Isparta.

Gerek, N., 1998. Türkiye'de İşçi Sağlığı ve İş Güvenliği, Ankara: Türk Metal Sendikası Yayınları, s.8.

Tekin, S., 2014. İşletmelerde İş Sağı̆̆ı Ve Güvenliğine Yapılan Yatırımların Maliyet Kazanç Analizi, ÇSGK, İş Teftiş Kurulu Başkanlığı, Ankara.

Uslu, V., 2014. İşletmelerde İş Güvenliği Performansı Ve İş Güvenliği Kültürü Algılamaları Arasındaki İlişki: Eskişehir İli Metal Sektöründe Bir Araştırma, Eskişehir Osmangazi Üniversitesi, Sosyal Bilimler Enstitüsü, Yüksek Lisans Tezi, Eskişehir.

Yıldırım, İ., Akyüz, K. C., Aydın, A., Alevli, C., 2015. Akdeniz Bölgesi Orman Ürünleri Sanayi Çalışanlarının İş Güvenliği Algılarının Belirlenmesi, Mühendislik Bilimleri ve Tasarım Dergisi, 3(3), ÖS: Ergonomi, 2015, 213-222, 2015 ISSN: 1308-6693, Süleyman Demirel Üniversitesi, Isparta. 